TITLE:

\title{
Preparation of Cu-Sn Layers on Polymer Substrate by Reduction- Diffusion Method Using Ionic Liquid Baths
}

\section{AUTHOR(S):}

Murase, Kuniaki; Ito, Akira; Ichii, Takashi; Sugimura, Hiroyuki

\section{CITATION:}

Murase, Kuniaki ... [et al]. Preparation of Cu-Sn Layers on Polymer Substrate by ReductionDiffusion Method Using Ionic Liquid Baths. Journal of The Electrochemical Society 2011, 158(6): D335-D341

\section{ISSUE DATE:}

2011

URL:

http://hdl.handle.net/2433/159459

RIGHT:

(C) 2011 ECS - The Electrochemical Society 


\section{Preparation of Cu-Sn Layers on Polymer Substrate by Reduction-Diffusion Method Using lonic Liquid Baths}

Kuniaki Murase, Akira Ito, Takashi Ichii and Hiroyuki Sugimura

J. Electrochem. Soc. 2011, Volume 158, Issue 6, Pages D335-D341. doi: 10.1149/1.3573984

Email alerting service
Receive free email alerts when new articles cite this article - sign up in the box at the top right corner of the article or click here

To subscribe to Journal of The Electrochemical Society go to: http://jes.ecsdl.org/subscriptions

(c) 2011 ECS - The Electrochemical Society 


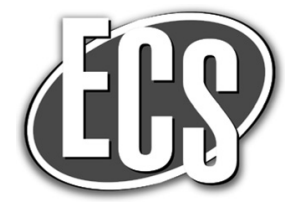

\section{Preparation of Cu-Sn Layers on Polymer Substrate by Reduction-Diffusion Method Using Ionic Liquid Baths}

Kuniaki Murase, ${ }^{*, z}$ Akira Ito, Takashi Ichii, and Hiroyuki Sugimura

Department of Materials Science and Engineering, Kyoto University, Sakyo-ku, Kyoto 606-8501, Japan

A novel metallization of non-conductive epoxy substrate with Cu-Sn "speculum alloy," or "white bronze," was performed through successive electrochemical processes: $(i)$ conventional electroless deposition of pure $\mathrm{Cu}$ layer and (ii) subsequent electrochemical alloying of the resulting pure $\mathrm{Cu}$ layer with $\mathrm{Sn}$ using an ionic liquid bath at $150^{\circ} \mathrm{C}$, a medium-low temperature. Availability of the $\mathrm{Sn}$ quasi-reference electrode for the alloying was verified, and the resulting compact and adhesive $\mathrm{Cu}-\mathrm{Sn}$ layers, composed of $\mathrm{Cu}_{6} \mathrm{Sn}_{5}$ and/or $\mathrm{Cu}_{3} \mathrm{Sn}$ intermetallic phases, were examined as an alternative to nickel plating. The abundance of the two intermetallic phases was found to be dependent on the alloying potential and duration, and was discussed in terms of alloy formation thermodynamics of the $\mathrm{Cu}-\mathrm{Sn}$ system.

(c) 2011 The Electrochemical Society. [DOI: 10.1149/1.3573984] All rights reserved.

Manuscript submitted February 4, 2011; revised manuscript received March 9, 2011. Published April 12, 2011.

Electrodeposition, or electroplating, of metals using cathodic reduction of corresponding metal ions in a solution is a basic technology for thin-layer processing to add desired properties to materials. While the phenomenon is nowadays applied for microfabrication in the fields of electronics and micromachining, the preparation of decorative and/or protective coatings is still the major purpose for which electrodeposition technology is used. Not only single metals but also alloy coatings are prepared by electrodeposition because electrodeposited alloys usually have enhanced properties for a given application compared with metals in the pure state. ${ }^{1}$ However, there are sometimes difficulties associated with stable process operation of alloy electrodeposition compared to the case of pure metal electrodeposition because the deposition baths contain more constituents: two or more metal salts, corresponding complex formers, buffering agents, and additives (e.g. brightener and leveler). This complexity of alloy electrodeposition baths can shorten the lifespan of the baths, and at the same time makes waste bath treatments complicated and energy-consuming even though electrodeposition is considered an environmentally-friendly technique for thin-layer processes.

As an alternative, we have been developing a reduction-diffusion (RD), or electrochemical alloying, method to form alloy layers using baths that each contain a single metal component. ${ }^{2,3}$ By using this method, silver-white $\mathrm{Cu}-\mathrm{Sn}$ alloy layers with composition 40 60 wt \% Sn (i.e. 26-45 atom \% Sn) called "speculum metal" or "white bronze" are obtained through two successive steps: ${ }^{3}(i)$ conventional electrodeposition of a pure $\mathrm{Cu}$ layer from an aqueous $\mathrm{CuSO}_{4}-\mathrm{H}_{2} \mathrm{SO}_{4}$ bath containing only $\mathrm{Cu}^{2+}$ ions as a metal component, followed by (ii) the RD alloying using an ionic liquid-based another bath containing $\mathrm{Sn}^{2+}$ ions. Here, the use of nonvolatile and nonflammable ionic liquid (IL) as a solvent renders it possible to raise the process temperature of $\mathrm{RD}$ alloying up to $150-190^{\circ} \mathrm{C}$, medium-low temperatures, and to speed up the alloy layer growth compared to that in aqueous baths, which cannot be operated at temperatures above $100^{\circ} \mathrm{C}$ in an ambient atmosphere. Although this method consists of two steps, the use of two separate baths each containing a single-metal component will extend the lifespan of the baths and also make waste bath treatment simpler and easier.

More recently, we demonstrated and briefly reported, as a short communication, ${ }^{4}$ that the $\mathrm{Cu}-\mathrm{Sn}$ alloy metallization of an epoxy substrate was also feasible by using electroless $\mathrm{Cu}$ deposition for step (i) above. Since the $\mathrm{Cu}$-Sn alloy layer is a promising alternative to an allergenic nickel underplating for decorative gold or chromium electroplating, the $\mathrm{Cu}-\mathrm{Sn}$ metallization of such non-conductive polymer substrates also needs to be developed. In the present paper, we report a more detailed analysis of resulting $\mathrm{Cu}-\mathrm{Sn}$ layers in order

\footnotetext{
* Electrochemical Society Active Member.

${ }^{2}$ E-mail: murase.kuniaki.2n@kyoto-u.ac.jp
}

to thoroughly discuss the mechanism and thermodynamics of the $\mathrm{Cu}-\mathrm{Sn}$ alloy formation, and to investigate some materials properties as an alternative to nickel coating. In addition, the electrochemical stability of pure Sn electrode was also examined to verify the validity of this electrode as a quasi-reference when employed in RD alloying.

\section{Experimental}

Preparation of electrolytic bath for alloying.-Ready-made hydrophobic IL, 1-ethyl-3-methylimidazolium bis[(trifluoromethyl)sulfonyl]amide $\left(\mathrm{EMI}-\mathrm{Tf}_{2} \mathrm{~N}\right.$; note that the $\mathrm{Tf}_{2} \mathrm{~N}^{-}$anion where $\mathrm{Tf}=\mathrm{SO}_{2} \mathrm{CF}_{3}$ is sometimes described as $\mathrm{TFSA}^{-}$or $\mathrm{TFSI}^{-}$), was purchased from Kanto Kagaku or Merck and used without further purification. Although another IL, trimethyl- $n$-hexylammonium bis[(trifluoromethyl)sulfonyl]amide, was tried previously, ${ }^{2,3}$ we used the thermally more stable EMI-Tf ${ }_{2} \mathrm{~N}$ in the present study. ${ }^{5} \operatorname{Tin}(\mathrm{II})$ salt, $\mathrm{Sn}\left(\mathrm{Tf}_{2} \mathrm{~N}\right)_{2}$, having the same anion as the IL was prepared by the acid-base reaction of $\mathrm{SnO}$ (Nacalai Tesque) with bis[(trifluoromethyl)sulfonyl]amine $\left(\mathrm{HNTf}_{2}\right.$; Fluka): $\mathrm{SnO}+2 \mathrm{HNTf}_{2} \rightarrow \mathrm{Sn}\left(\mathrm{Tf}_{2} \mathrm{~N}\right)_{2}+\mathrm{H}_{2} \mathrm{O}$. Here, powdery $\mathrm{SnO}$ was added to $1 \mathrm{~mol} \mathrm{dm}{ }^{-3}$ aqueous solution of $\mathrm{HNTf}_{2}$ and allowed to react at $70^{\circ} \mathrm{C}$ for more than $2 \mathrm{~h}$ under a nitrogen purge. Unreacted $\mathrm{SnO}$ was then filtered off and the water was vaporized away at $120^{\circ} \mathrm{C}$ under a nitrogen atmosphere, yielding a white hydrated $\operatorname{Sn}\left(\mathrm{Tf}_{2} \mathrm{~N}\right)_{2}$, which was further dried at $120^{\circ} \mathrm{C}$ for 3 days in a vacuum dryer. Note that the resulting $\operatorname{Sn}\left(\mathrm{Tf}_{2} \mathrm{~N}\right)_{2}$ salt may contain residual water and/or $\mathrm{HNTf}_{2}$. In the present RD process, however, these residues, if present, have an insignificant effect on the reduction of $\mathrm{Sn}^{2+}$ to $\mathrm{Sn}^{0}$, since the potential of $\mathrm{Sn}^{2+} / \mathrm{Sn}^{0}$ redox couple $\left(E_{\mathrm{Sn}^{2+} / \mathrm{Sn}^{0}}\right)$ is not that negative. We also expected that the most part of these volatile residues would spontaneously vaporize away when the bath for alloying (hereafter referred to as the "alloying bath") is operated at medium-low temperatures. To yield the alloying bath, the resulting $\operatorname{Sn}\left(\mathrm{Tf}_{2} \mathrm{~N}\right)_{2}$ salt was weighed and dissolved at $80^{\circ} \mathrm{C}$ into the EMI- $\mathrm{Tf}_{2} \mathrm{~N}$ in an open dry chamber (Daikin HRG-50A), in which the dew point was kept lower than $-50^{\circ} \mathrm{C}$; the $\mathrm{Sn}^{2+}$ ion concentration of the alloying bath was $0.05 \mathrm{~mol} \mathrm{dm}^{-3}$.

Cu substrate for alloying.- Unless otherwise noted, a thin layer of $\mathrm{Cu}$ (thickness, $\mathrm{ca}$. $0.5 \mu \mathrm{m}$ ) electrolessly deposited on a heatresistant high- $T_{\mathrm{g}}$ glass epoxy substrate using a conventional aqueous electroless plating bath (Okuno Chemical Ind., ATS Addcopper IW) was used as the $\mathrm{Cu}$ substrate for the RD alloying (see Figs. 3a and $3 b$ ). As a plastic substrate for decorative electroless plating, ABS (acrylonitrile-butadiene-styrene) resin is generally used; however, $\mathrm{ABS}$, a thermoplastic resin, cannot be used for the RD process at medium-low temperatures. Since the glass epoxy substrate was provided as a copper foil-clad laminate (Hitachi Chemical MCL-E679) for printed-circuit board manufacturing, the copper foil was first completely removed by dissolving it into an aqueous etchant 
containing $200 \mathrm{~g} \mathrm{dm}^{-3} \mathrm{Na}_{2} \mathrm{~S}_{2} \mathrm{O}_{8}$ (sodium persulfate) and $10 \mathrm{~g} \mathrm{dm}^{-3}$ $\mathrm{H}_{2} \mathrm{SO}_{4}$. In consequence, the resulting epoxy substrate before $\mathrm{Cu}$ electroless deposition already had a roughened surface. In some experiments, a $\mathrm{Cu}$ sheet (thickness, $0.5 \mathrm{~mm}$ ) polished with a \#2000 emery paper or a piece of the above copper foil-clad laminate (thickness of $\mathrm{Cu}$ foil, $18 \mu \mathrm{m}$ ) was used as needed for the RD alloying.

$R D$ alloying of $\mathrm{Cu}$ substrate.-Although the alloying bath was prepared in a dry chamber, the $\mathrm{Cu}-\mathrm{Sn}$ alloying experiments using the RD process were performed under atmospheric conditions (not in a dry chamber or a glove box). To avoid the oxidation of $\mathrm{Sn}^{2+}$ ions to tetravalent $\mathrm{Sn}(\mathrm{IV})$ state, however, the alloying bath was deaerated with nitrogen gas, while Tachikawa et al. reported that the oxidation of $\mathrm{Sn}$ (II) to $\mathrm{Sn}$ (IV) state does not take place within a wider electrochemical window of $\mathrm{BMP}_{-} \mathrm{Tf}_{2} \mathrm{~N}\left(\mathrm{BMP}^{+}: 1-n\right.$-butyl-1-methylpyrrolidinium). ${ }^{6}$ The alloying bath was thermostatted at $150^{\circ} \mathrm{C}$ unless otherwise noted, and was agitated at $\sim 500 \mathrm{rpm}$ using a magnetic stirring unit with a glass-coated stirring bar. Most alloying experiments were carried out using a potentiostatic method with a three-electrode configuration consisting of the above electroless $\mathrm{Cu}$ on epoxy substrate as a working electrode (i.e., cathode for RD alloying), Sn sheet as a counter electrode (i.e., anode for RD alloying), and Sn rod immersed into the same alloying bath as a quasireference electrode. While we employed a conventional set of potentiostat (Hokuto Denko HA-151) and coulometer (Hokuto Denko HF-201) for the alloying experiments, an integrated electrochemical analyzer (ALS/CHI model 660C) was utilized for the other electrochemical experiments such as polarization measurements.

Characterization of $\mathrm{Cu}$-Sn layers. - The surface morphology and average composition of the resulting $\mathrm{Cu}-\mathrm{Sn}$ layers were examined by scanning electron microscope (SEM, Keyence VE-7800) and associated energy dispersive X-ray spectrometer (EDX, EDAX Genesis 2000). A focused ion beam technique (FIB, JEOL JFIB2300) using Ga-ion source was employed to prepare cross-sectional samples and to obtain their secondary electron images. X-ray diffraction (XRD) measurements for phase identification were carried out with a scan mode of $2 \theta-\theta$ using a Rigaku RINT 2200 X-ray diffractometer fitted with a copper X-ray tube. To assess the colors of the layers objectively, optical reflection spectra were recorded with a UV-visible spectrometer (Hitachi U-3500) with integrating sphere. An X-ray photoelectron spectrometer (XPS, Kratos Analytical ESCA-3400) equipped with $\mathrm{Mg}-\mathrm{K} \alpha$ irradiation $(10 \mathrm{kV}, 10 \mathrm{~mA})$ and an Ar-ion sputtering system was used to examine the chemical state of $\mathrm{Cu}-\mathrm{Sn}$ layers at the surface.

\section{Results and Discussion}

Potential stability of Sn electrode as a reference.-Unlike the cases of aqueous systems, quasi-reference electrodes, or pseudoreference electrodes, are widely used for electrochemical measurements in non-aqueous systems like ILs. For ILs, a simple non-reactive $\mathrm{Ag}$ or Pt wire immersed in the same medium has commonly been used, ${ }^{7}$ but there is no guarantee that the potentials of these electrodes have long-term stability. In particular, the $\mathrm{Cu}-\mathrm{Sn}$ alloying in the present study requires rather strict potential control for more than 1 day; as hereinafter described, for example, to obtain $\mathrm{Cu}_{6} \mathrm{Sn}_{5}$ phase the alloying potential should be controlled at around $+5 \mathrm{mV}$ versus the equilibrium potential for $\mathrm{Sn}^{2+} / \mathrm{Sn}$ couple for the alloying bath. In our previous studies on metal electrodeposition from IL-based deposition baths, ${ }^{8-10}$ an $\mathrm{I}^{-} / \mathrm{I}_{3}{ }^{-}$electrode was used where $\mathrm{Pt}$ wire was placed in the same IL (without metal salts) containing $60 \mathrm{mmol} \mathrm{dm}^{-3}$ (n$\left.\mathrm{C}_{3} \mathrm{H}_{7}\right)_{4} \mathrm{NI}$ and $15 \mathrm{mmol} \mathrm{dm}{ }^{-3} \mathrm{I}_{2}$. The $\mathrm{I}^{-} / \mathrm{I}_{3}{ }^{-}$electrode is stable and reliable at room temperatures, but could not be so at medium-low temperatures because elemental iodine $\left(\mathrm{I}_{2}\right)$ existing in equilibrium can vaporize away at elevated temperatures. On the other hand, if the potential of an elemental Sn wire or Sn rod immersed in the alloying bath containing $\mathrm{Sn}^{2+}$ ions is stable and dominated by the redox $\mathrm{Sn}^{2+}+2 \mathrm{e}=\mathrm{Sn}$ then the $\mathrm{Sn}$ rod electrode will be a useful 'reference
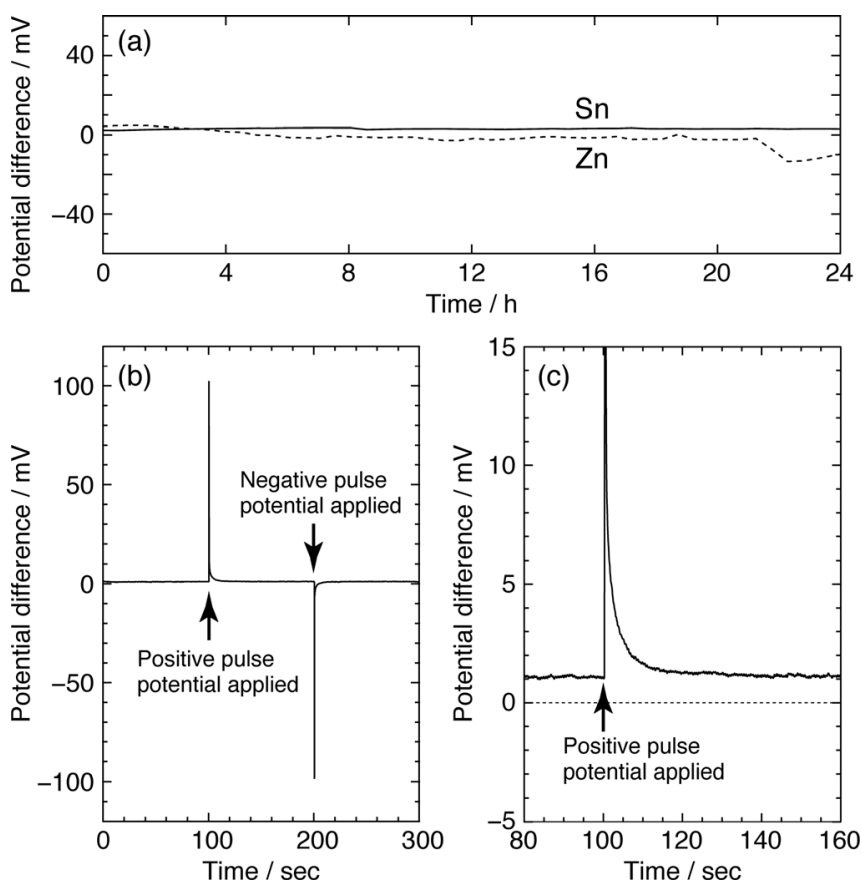

Figure 1. (a) Change in potential difference between two Sn electrodes or two $\mathrm{Zn}$ electrodes immersed in EMI- $\mathrm{Tf}_{2} \mathrm{~N}$ bath at $150^{\circ} \mathrm{C}$ containing $0.05 \mathrm{~mol}$ $\mathrm{dm}^{-3} \mathrm{Sn}\left(\mathrm{Tf}_{2} \mathrm{~N}\right)_{2}$ or $\mathrm{Zn}\left(\mathrm{Tf}_{2} \mathrm{~N}\right)_{2}$ and (b, c) change in open-circuit potential of Sn electrode immersed in EMI-Tf ${ }_{2} \mathrm{~N}$ at $150^{\circ} \mathrm{C}$ containing $0.05 \mathrm{~mol} \mathrm{dm}^{-3}$ $\mathrm{Sn}\left(\mathrm{Tf}_{2} \mathrm{~N}\right)_{2}$ when potential pulses of +100 and $-100 \mathrm{mV}$ vs. Sn rod were applied at times of 100 and $200 \mathrm{~s}$, respectively.

electrode of the first kind ${ }^{7}$ for the present RD alloying. Recently, Tachikawa et al. reported that the $\mathrm{Sn}^{2+} / \mathrm{Sn}$ redox couple in BMP$\mathrm{Tf}_{2} \mathrm{~N}$ is more reversible than other $\mathrm{M}^{2+} / \mathrm{M}(\mathrm{M}=\mathrm{Mn}, \mathrm{Fe}, \mathrm{Co}$, and $\mathrm{Zn})$ couples, ${ }^{6}$ suggesting that the $\mathrm{Sn}^{2+} / \mathrm{Sn}$ redox is applicable for reference.

To explore the availability of the Sn rod electrode, we performed several preliminary experiments. We assembled a three-electrode cell where the working, counter, and reference electrodes were all $\mathrm{Sn}$ rods immersed in the same alloying bath, i.e. EMI-Tf $_{2} \mathrm{~N}$ containing $0.05 \mathrm{~mol} \mathrm{dm}{ }^{-3} \mathrm{Sn}\left(\mathrm{Tf}_{2} \mathrm{~N}\right)_{2}$ at $150^{\circ} \mathrm{C}$. Figure $1 \mathrm{a}$ shows the time variation in open-circuit potential, that is, the potential difference between two Sn rods placed in the same bath. Although the potential difference was not zero, the value was always fairly small, i.e., about $2 \mathrm{mV}$ in this case, and almost constant for 1 day or more, indicating long-term stability of the $\mathrm{Sn}$ rod electrode. An analogous experiment carried out for comparison using a couple of $\mathrm{Zn}$ electrodes placed in EMI-Tf $f_{2} \mathrm{~N}$ containing $0.05 \mathrm{~mol} \mathrm{dm}^{-3} \mathrm{Zn}\left(\mathrm{Tf}_{2} \mathrm{~N}\right)_{2}$ at $150^{\circ} \mathrm{C}$ exhibited a more fluctuating potential difference. We then tried to apply potential pulses of +100 and $-100 \mathrm{mV} v s$. Sn rod, and the subsequent transient change in the open-circuit potential was monitored. As shown in Figs. $1 \mathrm{~b}$ and 1c, the open-circuit potential after each pulse returned to the original value within $20 \mathrm{~s}$, substantiating that the immersion potential of $\mathrm{Sn}$ electrode is stable against external electrical disturbance as is always required for a reference electrode. The immersion potential of the $\mathrm{Sn}$ rod at $50^{\circ} \mathrm{C}$ was $-0.12 \pm 0.01 \mathrm{~V} v s . \mathrm{I}^{-} / \mathrm{I}_{3}{ }^{-}$, which corresponds to $-0.27 \pm 0.01 v s$. ferrocenium/ferrocene $\left(\mathrm{Fc}^{+} / \mathrm{Fc}\right)$ couple. ${ }^{8}$

Following the results of verification, we measured a set of anodic and cathodic polarization curves and also carried out potentiostatic electrolysis at five different potentials: $+15,+5,-5,-10$, and $-20 \mathrm{mV}$ vs. Sn rod using the above three-electrode configuration. Figure 2a shows the current density during the potentiostatic electrolysis for $2 \mathrm{~h}$. Even under these relatively small polarizations a set of constant anodic (at +15 and $+5 \mathrm{mV}$ ) or cathodic (at $-5,-10$, and $-20 \mathrm{mV}$ ) currents were observed, and the absolute value of the current increased with increasing polarization. The weight changes 

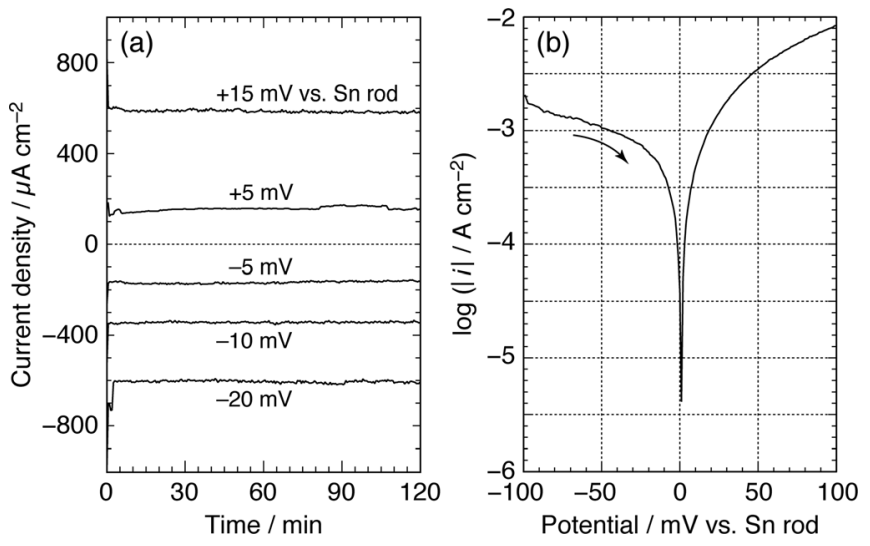

Figure 2. (a) Change in current density during potentiostatic electrolysis of $\mathrm{Sn}$ electrode at five different potentials and (b) polarization curves for $\mathrm{Sn}$ electrode with scan rate of $1 \mathrm{mV} \mathrm{s}^{-1}$. Electrolyte was EMI-Tf ${ }_{2} \mathrm{~N}$ at $150^{\circ} \mathrm{C}$ containing $0.05 \mathrm{~mol} \mathrm{dm}^{-3} \mathrm{Sn}\left(\mathrm{Tf}_{2} \mathrm{~N}\right)_{2}$.

of Sn working electrodes after each electrolysis provided the evidence of anodic dissolution $\left(\mathrm{Sn} \rightarrow \mathrm{Sn}^{2+}+2 \mathrm{e}\right.$ ) or cathodic deposition $\left(\mathrm{Sn}^{2+}+2 \mathrm{e} \rightarrow \mathrm{Sn}\right)$ under the anodic and cathodic polarization, respectively, indicating that the open-circuit potential of the Sn electrode is really dominated by the redox: $\mathrm{Sn}^{2+}+2 \mathrm{e}=\mathrm{Sn}$. We also confirmed that the current efficiency for the cathodic Sn deposition at -10 and $-20 \mathrm{mV}$ was $100 \%$. Figure $2 \mathrm{~b}$ depicts the polarization curves in Tafel form, which have a similar profile to those reported by Martindale et al. ${ }^{11}$ for $\mathrm{Sn}\left(\mathrm{Tf}_{2} \mathrm{~N}\right)_{2}$ in $\mathrm{BMP}-\mathrm{Tf}_{2} \mathrm{~N}$, a hydrophobic $\mathrm{Tf}_{2} \mathrm{~N}^{-}$-based IL. While the curves did not have clearly straight Tafel segments, the apparent exchange current density for the $\mathrm{Sn}^{2+} / \mathrm{Sn}$ redox roughly estimated using a tangent line at $+100 \mathrm{mV}$ is in the order of $10^{-3} \mathrm{~mA} \mathrm{~cm}^{-2}$.

Potential dependent $R D$ alloying.-In response to the above results, we performed a series of potentiostatic RD alloying experiments using the Sn rod as a reference electrode. After the RD alloying for $72 \mathrm{~h}$ at $+5,+10$, and $+20 \mathrm{mV} v$ s. Sn rod, a compact silverwhite or silver-gray $\mathrm{Cu}$-Sn alloy layer was obtained on the part immersed in the alloying bath, while the alloying at $+40 \mathrm{mV}$ gave a charcoal gray layer. Currents during the alloying decayed slowly with time (data not shown) as we previously reported for the alloying using TMHA- $\mathrm{Tf}_{2} \mathrm{~N}$ bath. ${ }^{2,3}$ When compared at a given time point, the current decreased with increasing alloying potential, i.e. with decreasing overpotential for reduction. Figure 3 shows the appearance and SEM images of the resulting layers, also depicting the images of the $\mathrm{Cu}$ layer before alloying (Fig. 3b) and the epoxy substrate (Fig. 3a). Owing to the roughened surface of the epoxy substrate, adhesions of the resulting $\mathrm{Cu}$-Sn layers were good due to an anchoring effect, and the layers could not be peeled off with a standard Scotch ${ }^{\circledR}$ adhesive tape. The surface morphology of the $\mathrm{Cu}-$ $\mathrm{Sn}$ layers was similar to that of the initial $\mathrm{Cu}$ layer, reflecting the mechanism of RD alloying where the alloy grows by inward diffusion of $\mathrm{Sn}$ atoms from the surface toward the interior without formation of bulk $\mathrm{Sn}$ phase. In consequence, surface morphological evolution like dendrite or nodule formation unrelated to the initial $\mathrm{Cu}$ surface was not recognized on the surface. Figure 4 shows a set of cross-sectional secondary electron images of initial $\mathrm{Cu}$ and the resulting $\mathrm{Cu}-\mathrm{Sn}$ layers alloyed at +5 and $+20 \mathrm{mV}$. As is often the case with electroless plating, the initial $\mathrm{Cu}$ was conformally grown on the roughened epoxy substrate. While the resulting $\mathrm{Cu}$-Sn layers

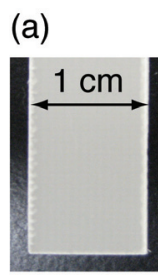

(c)

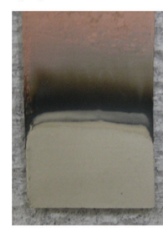

(e)

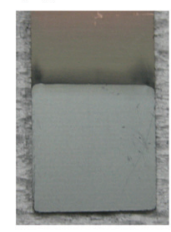

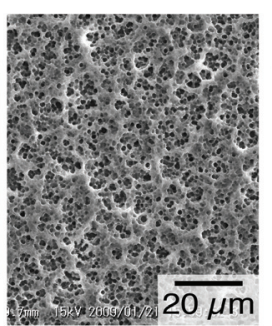
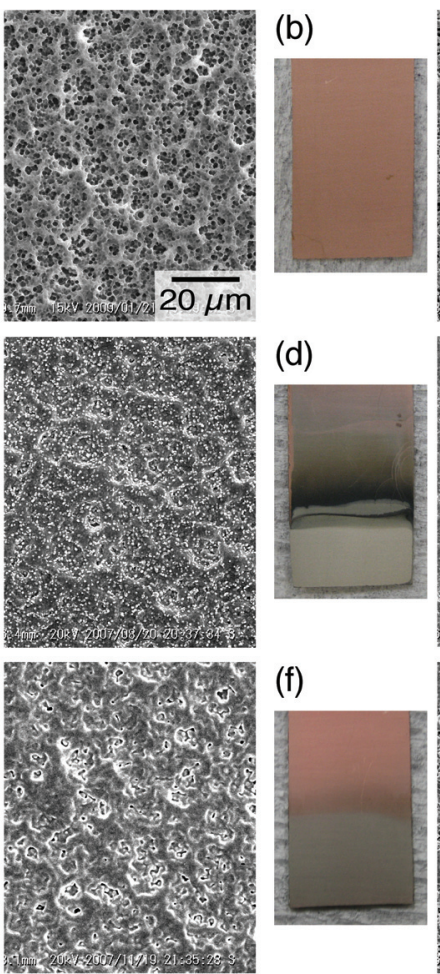

(f)

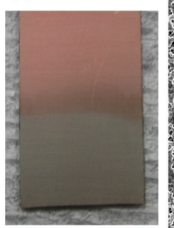

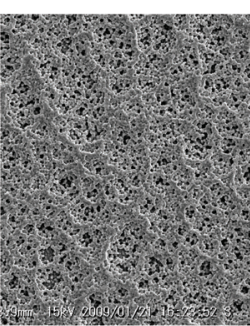
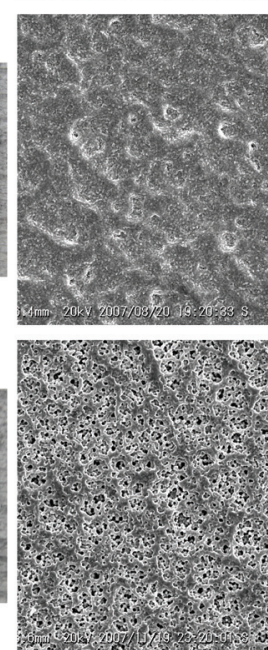

Figure 3. (Color online) Appearance and plan-view SEM images of (a) heatresistant epoxy substrate, (b) electroless $\mathrm{Cu}$ layer on the substrate, and (c-f) $\mathrm{Cu}-\mathrm{Sn}$ layers prepared by potentiostatic alloying for $72 \mathrm{~h}$ at $150^{\circ} \mathrm{C}$ using EMI$\mathrm{Tf}_{2} \mathrm{~N}$ bath containing $0.05 \mathrm{~mol} \mathrm{dm} \mathrm{dm}^{-3} \mathrm{Sn}\left(\mathrm{Tf}_{2} \mathrm{~N}\right)_{2}$. Alloying potentials were (c) $+5 \mathrm{mV}$, (d) $+10 \mathrm{mV}$, (e) $+20 \mathrm{mV}$, and (f) $+40 \mathrm{mV} v$ s. Sn rod.
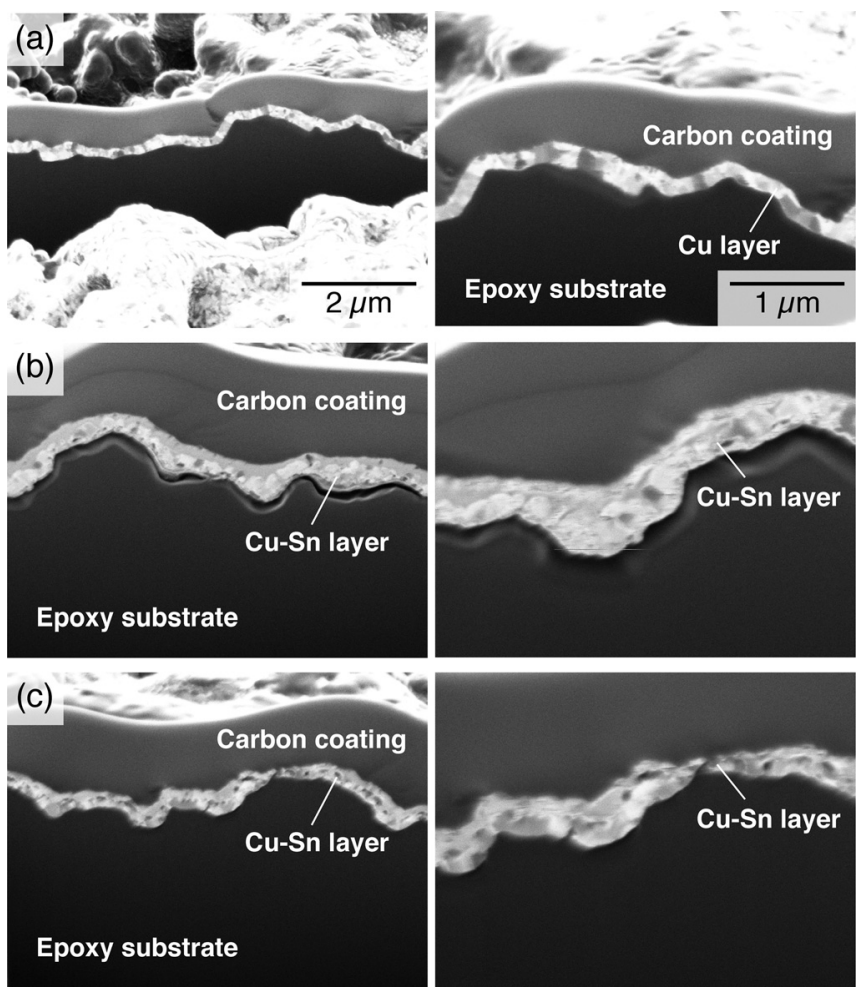

Figure 4. Cross-sectional secondary electron images of (a) electroless $\mathrm{Cu}$ layer on heat-resistant epoxy substrate and (b, c) $\mathrm{Cu}-\mathrm{Sn}$ layers prepared by potentiostatic alloying for $72 \mathrm{~h}$ at $150^{\circ} \mathrm{C}$ using EMI-Tf $\mathrm{f}_{2} \mathrm{~N}$ bath containing $0.05 \mathrm{~mol} \mathrm{dm}{ }^{-3} \mathrm{Sn}\left(\mathrm{Tf}_{2} \mathrm{~N}\right)_{2}$. Alloying potentials were (b) $+5 \mathrm{mV}$ and $(\mathrm{c})+20$ $\mathrm{mV}$ vs. Sn rod. Images were taken at $60^{\circ}$ tilted to the surface normal. Images on the right side are enlargements of those on the left. 
(a)

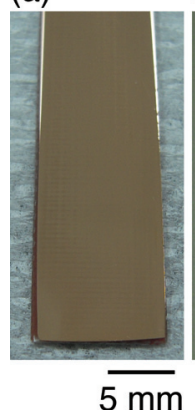

(b)

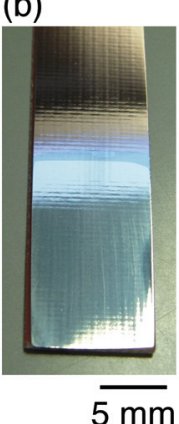

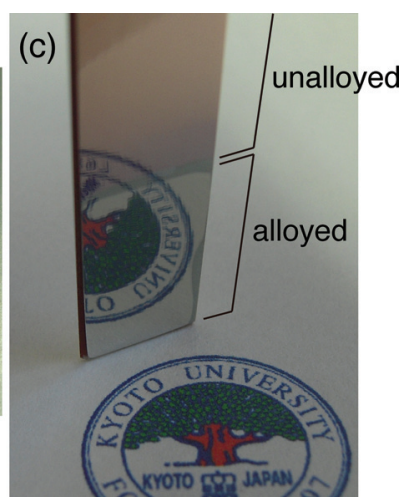

Figure 5. (Color online) Appearance of glossy $\mathrm{Cu}$ foil-clad laminate (a) before and (b, c) after potentiostatic alloying for $72 \mathrm{~h}$ at $5 \mathrm{mV} v s$. Sn rod and $150^{\circ} \mathrm{C}$ using EMI-Tf ${ }_{2} \mathrm{~N}$ bath containing $0.05 \mathrm{~mol} \mathrm{dm}{ }^{-3} \mathrm{Sn}\left(\mathrm{Tf}_{2} \mathrm{~N}\right)_{2}$.

apparently kept the initial uniformity, a second look confirms that concave portions of the initial layer grew somewhat thicker than convex portions. This also reflects the mechanism of RD alloying where the total amount of Sn atoms introduced is not governed by the surface area but determined by the stoichiometry, that is the amount of initial $\mathrm{Cu}$ atoms. As described later, the main $\mathrm{Cu}-\mathrm{Sn}$ phases obtained at +5 and $+20 \mathrm{mV}$ were $\mathrm{Cu}_{6} \mathrm{Sn}_{5}$ and $\mathrm{Cu}_{3} \mathrm{Sn}$, respectively, hence the former layer is thicker than the latter.

Since the initial $\mathrm{Cu}$ surface was rather rough (Fig. 4) with a matte appearance, all the resulting $\mathrm{Cu}-\mathrm{Sn}$ layers were also lusterless (Fig. 3 ). In contrast, the alloying of glossy $\mathrm{Cu}$ foil-clad laminate under the same conditions (i.e. $+5 \mathrm{mV}$ ) gave a lustrous $\mathrm{Cu}-\mathrm{Sn}$ surface as shown in Fig. 5, also indicating that the initial $\mathrm{Cu}$ surface is a key to obtaining a flat and smooth speculum layer. In other words, as long as a lustrous $\mathrm{Cu}$ layer is prepared on a resin substrate using any wellestablished technique, the subsequent alloying bath does not always have to contain brightening and/or leveling agents as additives.

Figure 6 shows XRD patterns for the same samples as in Fig. 3. On the phase diagram of the $\mathrm{Cu}-\mathrm{Sn}$ binary system, the thermodynamically stable $\mathrm{Cu}-\mathrm{Sn}$ intermetallic phases at $150^{\circ} \mathrm{C}$ are $\eta^{\prime}-\mathrm{Cu}_{6} \mathrm{Sn}_{5}$ (ca. 45 atom \% Sn) and $\varepsilon-\mathrm{Cu}_{3} \mathrm{Sn}\left(24.5-25.9\right.$ atom \% Sn). ${ }^{12}$ The layers alloyed at +5 and $+20 \mathrm{mV}$ were single-phase $\mathrm{Cu}_{6} \mathrm{Sn}_{5}$ and $\mathrm{Cu}_{3} \mathrm{Sn}$, respectively, while the layer obtained at $+10 \mathrm{mV}$ was a mixture of these two phases. These layers gave no diffraction of $\alpha-\mathrm{Cu}$ (i.e. elemental fcc-Cu) or $\alpha-\mathrm{Cu}(\mathrm{Sn})$ phase (i.e. fcc-Cu dissolving $\mathrm{Sn}$ atoms as a solid solution), indicating that all the initial $\mathrm{Cu}$ layers were converted to $\mathrm{Cu}-\mathrm{Sn}$ alloys. In addition, diffraction due to $\beta$-Sn phase (i.e. elemental $\mathrm{Sn}$ ), was also not found, since the alloying potentials are positive than $0 \mathrm{mV} v s$. Sn rod. We also confirmed by XRD that electrolysis at a slightly negative potential, $-5 \mathrm{mV}$, really gave a pure $\beta$-Sn phase on the $\mathrm{Cu}$ substrate (data not shown). The potential-dependent alloy formation was also supported by a set of gross composition data from EDX analysis: The compositions of the layers prepared at $+5,+10$, and $+20 \mathrm{mV}$ were 45.9 , 40.7, and 26.6 atom \% Sn, respectively. In other words, Sn-rich phase, i.e. $\mathrm{Cu}_{6} \mathrm{Sn}_{5}$, whose tin activity $a_{\mathrm{Sn}}$ is higher than $\mathrm{Cu}_{3} \mathrm{Sn}$, was obtained at relatively low potential, while a lower $a_{\mathrm{Sn}}$ phase, i.e. $\mathrm{Cu}_{3} \mathrm{Sn}$, was formed at higher potentials. Unlike the cases of +5 to $+20 \mathrm{mV}$, the main phase obtained at $+40 \mathrm{mV}$ was $\alpha-\mathrm{Cu}(\mathrm{Sn})$ phase (Fig. 6f) containing 2.4 atom \% Sn, probably due to the lack of time for sufficient alloying. As discussed later, the thermodynamically stable phase at $+40 \mathrm{mV}$ is $\mathrm{Cu}_{3} \mathrm{Sn}$.

Thermodynamics and growth mechanism.-To gain thermodynamic insight into the dependence of the alloying potentials on the formation of intermetallic phases, the thermodynamically stable phase for a given electrode potential was calculated as we previously reported for $\mathrm{Cu}-\mathrm{Sn}$ alloying with a TMHA-Tf ${ }_{2} \mathrm{~N}$ bath at $130^{\circ} \mathrm{C} .^{3}$ Here, we used literature data of Gibbs energy of formation ${ }^{13}$

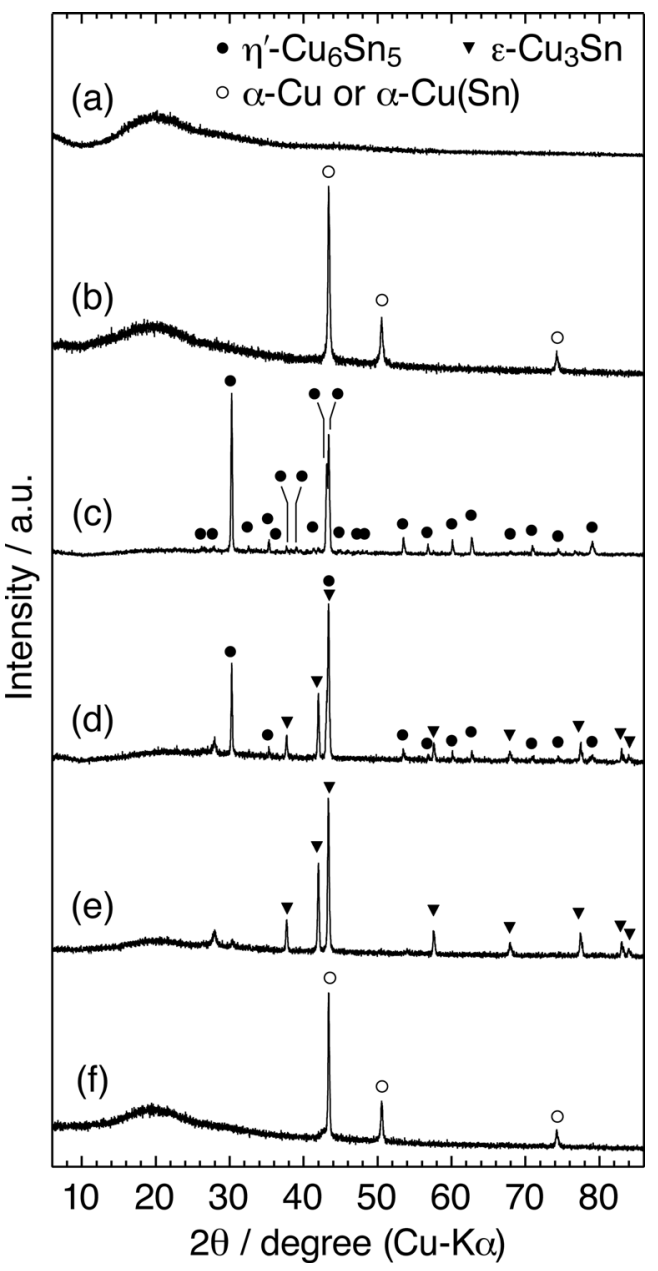

Figure 6. X-ray diffraction patterns of the same samples as in Fig. 3.

$$
3 \mathrm{Cu}+\mathrm{Sn}=\mathrm{Cu}_{3} \mathrm{Sn} \quad G^{\circ} \mathrm{Cu}_{3} \mathrm{Sn}\left(\mathrm{J} \mathrm{mol}^{-1}\right)=-32776.8-0.8172 T
$$

$6 \mathrm{Cu}+5 \mathrm{Sn}=\mathrm{Cu}_{6} \mathrm{Sn}_{5} \quad G^{\circ} \mathrm{Cu}_{6} \mathrm{Sn}_{5}\left(\mathrm{~J} \mathrm{~mol}^{-1}\right)=-78426.7+4.4649 T$

where $T$ is the absolute temperature, and considered four stable phases, i.e. $\beta-\mathrm{Sn}, \mathrm{Cu}_{6} \mathrm{Sn}_{5}, \mathrm{Cu}_{3} \mathrm{Sn}$, and $\alpha-\mathrm{Cu}(\mathrm{Sn})$. Figure 7 depicts the activity of tin $\left(a_{\mathrm{Sn}}\right)$ at $150^{\circ} \mathrm{C}(T=423 \mathrm{~K})$ as a function of tin content. The Nernst equation for $\mathrm{Sn}^{2+}+2 \mathrm{e}=\mathrm{Sn}^{0}$ redox is given by

$$
E_{\mathrm{Sn}^{2+} / \mathrm{Sn}^{0}}=E_{\mathrm{Sn}^{2+} / \mathrm{Sn}^{0}}^{\circ}-\frac{R T}{2 F} \ln \frac{a_{\mathrm{Sn}}}{a_{\mathrm{Sn}^{2+}}}
$$

where $a_{\mathrm{Sn}}{ }^{2+}$ is the activity of $\mathrm{Sn}^{2+}$ ions in the alloying bath; the other symbols $E, E^{\circ}, R$, and $F$ have the usual meanings. Note that $\mathrm{Sn}^{0}$ stands for zero-valent tin including both elemental $\mathrm{Sn}$ and tin in $\mathrm{Cu}-\mathrm{Sn}$ alloys. Since $a_{\mathrm{Sn}}$ of elemental $\mathrm{Sn}$ is 1 by convention, the immersion potential of the $\mathrm{Sn}$ rod reference electrode is

$$
E_{\mathrm{Sn}^{2+} / \mathrm{Sn}^{0}}=E_{\mathrm{Sn}^{2+} / \mathrm{Sn}^{0}}^{\circ}-\frac{R T}{2 F} \ln \frac{1}{a_{\mathrm{Sn}^{2+}}} \equiv 0 \text { vs. Sn rod }
$$

given that the immersion potential of $\mathrm{Sn}$ rod is dominated by $\mathrm{Sn}^{2+}+2 \mathrm{e}=\mathrm{Sn}$ redox, and hence the deposition of pure $\mathrm{Sn}$ takes place at potentials negative to the immersion potential. In contrast, since $a_{\mathrm{Sn}}$ of $\mathrm{Cu}-\mathrm{Sn}$ alloys is less than unity $\left(a_{\mathrm{Sn}}<1\right), \mathrm{Cu}-\mathrm{Sn}$ alloys forms without codeposition of pure $\mathrm{Sn}$ at positive potentials as 


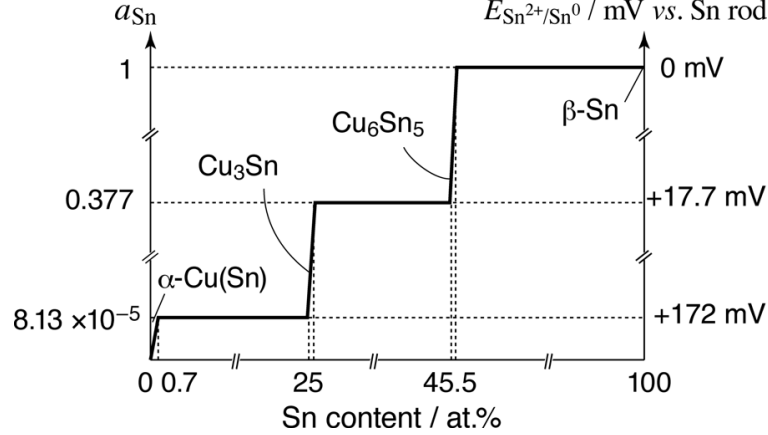

Figure 7. Activity of tin $a_{\mathrm{Sn}}$ and corresponding redox potential $E_{\mathrm{Sn}^{2}+\mathrm{Sn}^{0}} v s$. Sn rod as a function of tin content of Cu-Sn alloys calculated using thermochemical data for $\mathrm{Cu}_{6} \mathrm{Sn}_{5}$ and $\mathrm{Cu}_{3} \mathrm{Sn}$ intermetallic phases.

described in the preceding section. According to Eqs. 3 and 4, the potential $E_{\mathrm{Sn}^{2+} / \mathrm{Sn}^{0}}$ for alloy formation with reference to the $\mathrm{Sn}$ rod electrode is

$$
E_{\mathrm{Sn}^{2+} / \mathrm{Sn}^{0}}(v s . \mathrm{Sn} \text { rod })=-\frac{R T}{2 F} \ln a_{\mathrm{Sn}}
$$

The right ordinate of Fig. 7 is the potential $E_{\mathrm{Sn}^{2+} / \mathrm{Sn}^{0}}$ corresponding to $a_{\mathrm{Sn}}$ values. The important thing is that, so long as the $\mathrm{Sn}$ rod electrode is employed and works properly, neither the activity of $\mathrm{Sn}^{2+}$ ions $\left(a_{\mathrm{Sn}^{2+}}\right)$ nor the solvent used for the alloying, governs $E_{\mathrm{Sn}^{2+} / \mathrm{Sn}^{0}}$ (vs. Sn rod) values.

Figure 7 indicates that $\mathrm{Cu}_{6} \mathrm{Sn}_{5}, \mathrm{Cu}_{3} \mathrm{Sn}$, and $\alpha-\mathrm{Cu}(\mathrm{Sn})$ phases are thermodynamically stable in the potential ranges $0<E_{\mathrm{Sn}^{2+} / \mathrm{Sn}^{0}}$ $<+17.7 \mathrm{mV},+17.7<E_{\mathrm{Sn}^{2+} / \mathrm{Sn}^{0}}<+172 \mathrm{mV}$, and $E_{\mathrm{Sn}^{2+} / \mathrm{Sn}^{0}}$ $>+172 \mathrm{mV}$, respectively. Thus the experimentally obtained phases, $\mathrm{Cu}_{6} \mathrm{Sn}_{5}$ at $+5 \mathrm{mV}$ and $\mathrm{Cu}_{3} \mathrm{Sn}$ at $+20 \mathrm{mV}$, were well accounted for by the thermodynamics. Meanwhile, the resulting alloy at $+10 \mathrm{mV}$ was a mixture of $\mathrm{Cu}_{6} \mathrm{Sn}_{5}$ and $\mathrm{Cu}_{3} \mathrm{Sn}$, although a single-phase $\mathrm{Cu}_{6} \mathrm{Sn}_{5}$ is thermodynamically expected. The reason for the discrepancy is unclear, but we think that it is due to a kinetic factor of the alloying, like the case of alloying at $+40 \mathrm{mV}$, where $\alpha-\mathrm{Cu}(\mathrm{Sn})$ phase formed in spite of the expected phase, i.e. $\mathrm{Cu}_{3} \mathrm{Sn}$.
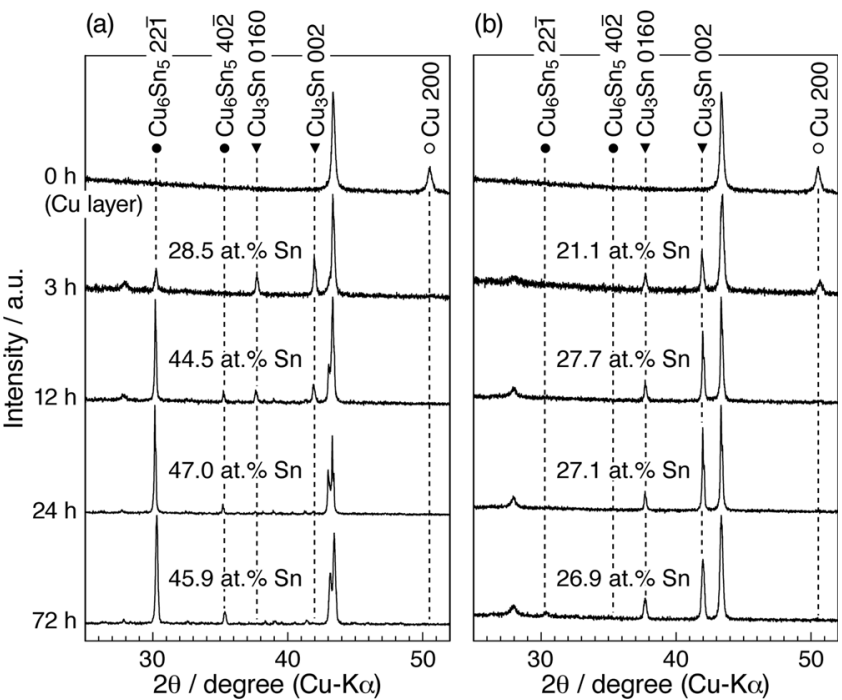

Figure 8. X-ray diffraction patterns and gross compositions of $\mathrm{Cu}$ thin layers before and after alloying for $3-72 \mathrm{~h}$ at $150^{\circ} \mathrm{C}$ using EMI-Tf ${ }_{2} \mathrm{~N}$ bath containing $0.05 \mathrm{~mol} \mathrm{dm}^{-3} \mathrm{Sn}\left(\mathrm{Tf}_{2} \mathrm{~N}\right)_{2}$. Alloying potentials were (a) $+5 \mathrm{mV}$ and (b) $+20 \mathrm{mV} v s$. Sn rod. Indices of diffraction lines are based on JCPDS No. 45-1488 $\left(\mathrm{Cu}_{6} \mathrm{Sn}_{5}\right), 01-1488\left(\mathrm{Cu}_{3} \mathrm{Sn}\right)$, and 04-0836 $(\mathrm{Cu})$.
In order to understand the alloy formation process in more detail, the change in phase during the alloying for $72 \mathrm{~h}$ was examined for two alloying potentials, +5 and $+20 \mathrm{mV}$; Fig. 8 shows the changes in XRD patterns and gross compositions determined by EDX. At $+5 \mathrm{mV}, \mathrm{Cu}_{6} \mathrm{Sn}_{5}$ phase appeared throughout the alloying for $72 \mathrm{~h}$, while in the primary step of $3-12 \mathrm{~h}$ alloying $\mathrm{Cu}_{3} \mathrm{Sn}$ phases were also recognized. In contrast, at $+20 \mathrm{mV}$, only $\mathrm{Cu}_{3}$ Sn phase was formed throughout the alloying for $72 \mathrm{~h}$. Based on the above thermodynamic discussion, it is reasonable that, at $+20 \mathrm{mV}, \mathrm{Cu}_{3} \mathrm{Sn}$ compound is initially formed on the surface and grows into the substrate by the diffusion of resulting $\mathrm{Sn}$ atoms until the whole $\mathrm{Cu}$ substrate is converted to single-phase $\mathrm{Cu}_{3} \mathrm{Sn}$. Similarly, at $+5 \mathrm{mV}$, $\mathrm{Cu}_{6} \mathrm{Sn}_{5}$ compound is preferentially formed on the uppermost surface, but in this case $\mathrm{Cu}_{3} \mathrm{Sn}$ compound is also formed at the boundary between the surface $\mathrm{Cu}_{6} \mathrm{Sn}_{5}$ layer and the unalloyed $\mathrm{Cu}$ underneath by a reaction diffusion in the $\mathrm{Cu}-\mathrm{Sn}$ system. The entire $\mathrm{Cu}$ substrate is converted to single-phase $\mathrm{Cu}_{6} \mathrm{Sn}_{5}$ that is thermodynamically stable at $+5 \mathrm{mV}$ if a sufficient amount of tin atoms are supplied and enough time passes for them to diffuse into the substrate. Otherwise the $\mathrm{Cu}_{3} \mathrm{Sn}$ phase remains and the resulting alloy layer is composed of $\mathrm{Cu}_{6} \mathrm{Sn}_{5}$ and $\mathrm{Cu}_{3} \mathrm{Sn}$, like the case of the alloying at $+10 \mathrm{mV}$. Figure 9 gives the cross sectional SEM image and the profile of EDX line analysis for the $\mathrm{Cu}-\mathrm{Sn}$ layer. Here, we used a polished $\mathrm{Cu}$ sheet (thickness, $0.5 \mathrm{~mm}$ ) as a starting $\mathrm{Cu}$ substrate and the alloying was carried out for $72 \mathrm{~h}$ with a galvanic contact method at $190^{\circ} \mathrm{C}$, a higher temperature, to accelerate the diffusion. In the galvanic contact method, the potential of the cathode during the alloying is spontaneously kept at around +2 to $+5 \mathrm{mV}^{2}$ which thermodynamically should result in the formation of $\mathrm{Cu}_{6} \mathrm{Sn}_{5}$ phase. The resulting $\mathrm{Cu}-\mathrm{Sn}$ layer at the surface of the $\mathrm{Cu}$ sheet had a clear

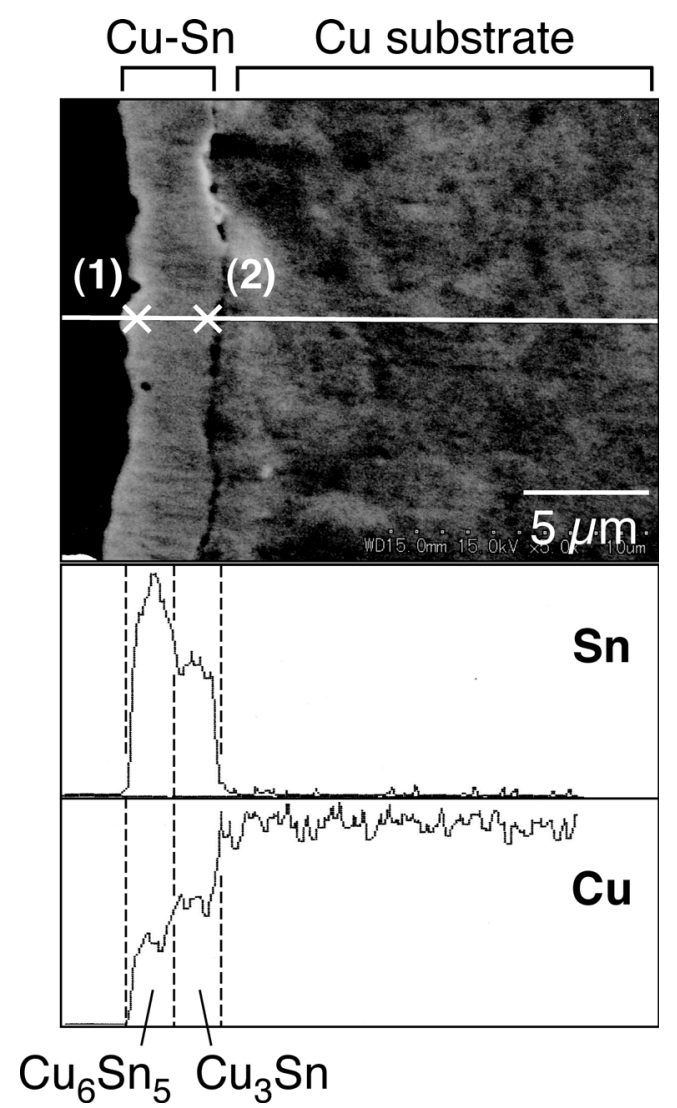

Figure 9. SEM image and EDX line profile of the cross-section of $\mathrm{Cu}-\mathrm{Sn}$ layer grown on a $\mathrm{Cu}$ sheet by galvanic contact alloying for $72 \mathrm{~h}$ at $150^{\circ} \mathrm{C}$ using EMI-Tf ${ }_{2} \mathrm{~N}$ bath containing $0.05 \mathrm{~mol} \mathrm{dm} \mathrm{dm}^{-3} \mathrm{Sn}\left(\mathrm{Tf}_{2} \mathrm{~N}\right)_{2}$. EDX point analysis data for outer and inner parts are (1) 46 atom \% Sn and (2) 26 atom $\% \mathrm{Sn}$. 
composition difference; the outer parts of the layer had compositions corresponding to $\mathrm{Cu}_{6} \mathrm{Sn}_{5}$ (Sn-rich) phase and the inner parts were $\mathrm{Cu}_{3} \mathrm{Sn}\left(\mathrm{Cu}\right.$-rich) phase. In other words, a $\mathrm{Cu}$-rich $\mathrm{Cu}_{3} \mathrm{Sn}$ phase is located between the substrate $\mathrm{Cu}$ and $\mathrm{Sn}$-rich $\mathrm{Cu}_{6} \mathrm{Sn}_{5}$ phase. The presence of such a composition gradient also supports that the $\mathrm{Cu}$ $\mathrm{Sn}$ layers are really grown by interdiffusion of $\mathrm{Cu}$ and $\mathrm{Sn}$ atoms. In any case, Fig. 8 indicates that the alloying of $\mathrm{Cu}$ substrate (thickness, $c a .0 .5 \mu \mathrm{m}$ ) at +5 and $+20 \mathrm{mV}$ completed within $24 \mathrm{~h}$.

Materials properties of single-phase $\mathrm{Cu}_{6} \mathrm{Sn}_{5}$ and $\mathrm{Cu}_{3} \mathrm{Sn}$ layers.- The $\mathrm{Cu}$-Sn phase diagram ${ }^{12}$ indicates that, upon cooling of a $\mathrm{Cu}-\mathrm{Sn}$ melt containing 45.5 atom $\% \mathrm{Sn}, \mathrm{Cu}_{6} \mathrm{Sn}_{5}$ phase ( $\eta$ phase) forms through a peritectic reaction between $\mathrm{Cu}_{3} \mathrm{Sn}$ phase ( $\varepsilon$ phase) and the liquid phase, implying difficulty in the preparation of singlephase $\mathrm{Cu}_{6} \mathrm{Sn}_{5}$ by a simple fusion method. While aqueous alloy electrodeposition can prepare almost-single-phase $\mathrm{Cu}_{6} \mathrm{Sn}_{5},{ }^{14}$ the electrodeposition of single-phase $\mathrm{Cu}_{3} \mathrm{Sn}$ has not been achieved to date. In contrast, our RD alloying can easily create both $\mathrm{Cu}_{6} \mathrm{Sn}_{5}$ and $\mathrm{Cu}_{3} \mathrm{Sn}$ single-phases using potential and time control, and therefore it will be a useful tool for comparing the various physicochemical properties of these single-phase layers. In this study, differences in color and anodic property, as important surface properties when using the $\mathrm{Cu}-\mathrm{Sn}$ layer for the underplating, were examined. The visible reflection spectra of $\mathrm{Cu}_{6} \mathrm{Sn}_{5}$ and $\mathrm{Cu}_{3} \mathrm{Sn}$ layers prepared at +5 and $+20 \mathrm{mV}$ are shown in Fig. 10 together with spectra of the surfaces of $\mathrm{Ni}, \mathrm{Cu}$, and $\mathrm{Ag}$ sheets for comparison. As shown in Fig. 3, both $\mathrm{Cu}_{6} \mathrm{Sn}_{5}$ and $\mathrm{Cu}_{3} \mathrm{Sn}$ layers were silver-white or silvergray, but the $\mathrm{Cu}_{3} \mathrm{Sn}$ layer looked somewhat bluish. In fact, their reflection spectra gave different profiles, accounting for the difference in color of each layer. The reflectance of the $\mathrm{Cu}_{6} \mathrm{Sn}_{5}$ layer gradually and monotonically increased with increasing wavelength like $\mathrm{Ni}$ and $\mathrm{Ag}$, while that of $\mathrm{Cu}_{3} \mathrm{Sn}$ had a local minimum at around $680 \mathrm{~nm}$, of which the complementary color is blue-green. The important point is that the spectrum for the $\mathrm{Cu}_{6} \mathrm{Sn}_{5}$ layer resembles that for Ni. As noted in the Introduction, a "speculum metal" layer with 40-60 wt \% Sn is anticipated as an alternative to nickel underplating, and one reason for this is that the $\mathrm{Cu}-\mathrm{Sn}$ alloy has a pleasing silver-white color like nickel which enhances the brightness of, for example, gold plating over it. According to the $\mathrm{Cu}-\mathrm{Sn}$ phase dia-

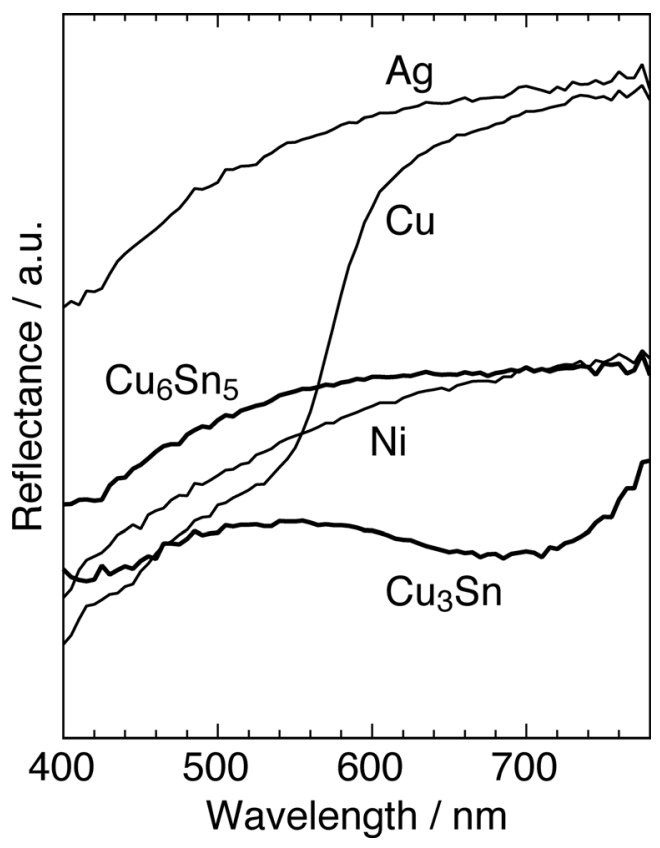

Figure 10. Visible reflection spectra of single-phase $\mathrm{Cu}_{6} \mathrm{Sn}_{5}$ and $\mathrm{Cu}_{3} \mathrm{Sn}$ layers prepared by the alloying of $\mathrm{Cu}$ layer at +5 and $+20 \mathrm{mV} v s$. Sn rod, respectively, using EMI-Tf ${ }_{2} \mathrm{~N}$ bath containing $0.05 \mathrm{~mol} \mathrm{dm}^{-3} \mathrm{Sn}\left(\mathrm{Tf}_{2} \mathrm{~N}\right)_{2}$ at $150^{\circ} \mathrm{C}$. The spectra of $\mathrm{Ni}, \mathrm{Cu}$, and $\mathrm{Ag}$ are also depicted.

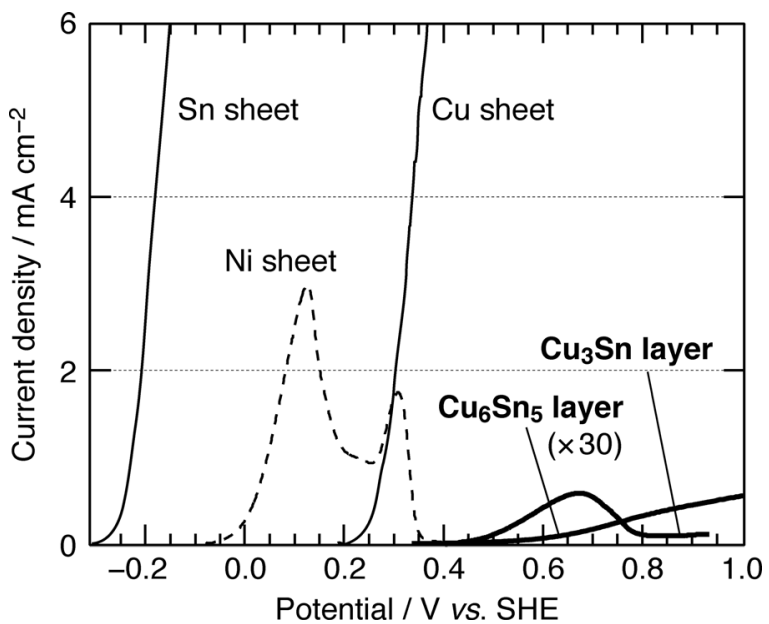

Figure 11. A set of typical anodic polarization curves for the same singlephase $\mathrm{Cu}_{6} \mathrm{Sn}_{5}$ and $\mathrm{Cu}_{3} \mathrm{Sn}$ layers as in Fig. 10 immersed in $0.05 \mathrm{~mol} \mathrm{dm}^{-3}$ $\mathrm{H}_{2} \mathrm{SO}_{4}$ aqueous solution. The curves for pure $\mathrm{Ni}, \mathrm{Cu}$, and $\mathrm{Sn}$ electrodes are also shown. Scan rate was $0.5 \mathrm{mV} \mathrm{s}^{-1}$ for all samples.

gram, ${ }^{12}$ the alloy of $40-60 \mathrm{wt} \%$ Sn generally consists of two phases, $\mathrm{Cu}_{6} \mathrm{Sn}_{5}$ and $\mathrm{Cu}_{3} \mathrm{Sn}$. The above result indicates the nickellike color is mainly due to the presence of $\mathrm{Cu}_{6} \mathrm{Sn}_{5}$ intermetallic phase rather than $\mathrm{Cu}_{3} \mathrm{Sn}$ phase; the mixed layer comprising $\mathrm{Cu}_{6} \mathrm{Sn}_{5}$ phase obtained at $+10 \mathrm{mV}$ also has a nickel-like color without bluish coloring.

If it is to be used as an alternative to Ni underplating, knowledge of the corrosion behavior of a $\mathrm{Cu}-\mathrm{Sn}$ layer will be of importance. Figure 11 shows a set of anodic polarization curves for the singlephase $\mathrm{Cu}_{6} \mathrm{Sn}_{5}$ and $\mathrm{Cu}_{3} \mathrm{Sn}$ layers obtained in diluted sulfuric acid (50 mmol dm $\left.{ }^{-3} \mathrm{H}_{2} \mathrm{SO}_{4}\right)$ at $25^{\circ} \mathrm{C}$. Here, the potential was measured with a $\mathrm{Ag} / \mathrm{AgCl}\left(3.33 \mathrm{~mol} \mathrm{dm}^{-3} \mathrm{KCl}\right)$ reference electrode, and is quoted versus the standard hydrogen electrode (SHE). Corrosion potentials of $\mathrm{Cu}_{6} \mathrm{Sn}_{5}$ and $\mathrm{Cu}_{3} \mathrm{Sn}$ were rather positive, +403 and $+334 \mathrm{mV}$ vs. SHE, respectively, and were higher than those of pure $\mathrm{Ni}(-81$ $\mathrm{mV}), \mathrm{Cu}(+182 \mathrm{mV})$, and $\mathrm{Sn}(-312 \mathrm{mV})$. When polarized positively from the corrosion potentials, the $\mathrm{Cu}_{6} \mathrm{Sn}_{5}$ and $\mathrm{Cu}_{3} \mathrm{Sn}$ layers thoroughly passivated, whereas pure $\mathrm{Cu}$ and $\mathrm{Sn}$ readily dissolved anodically. Although $\mathrm{Ni}$ was also passivated, the observed critical current density for passivation was $c a .3 \mathrm{~mA} \mathrm{~cm}{ }^{-2}$, which was

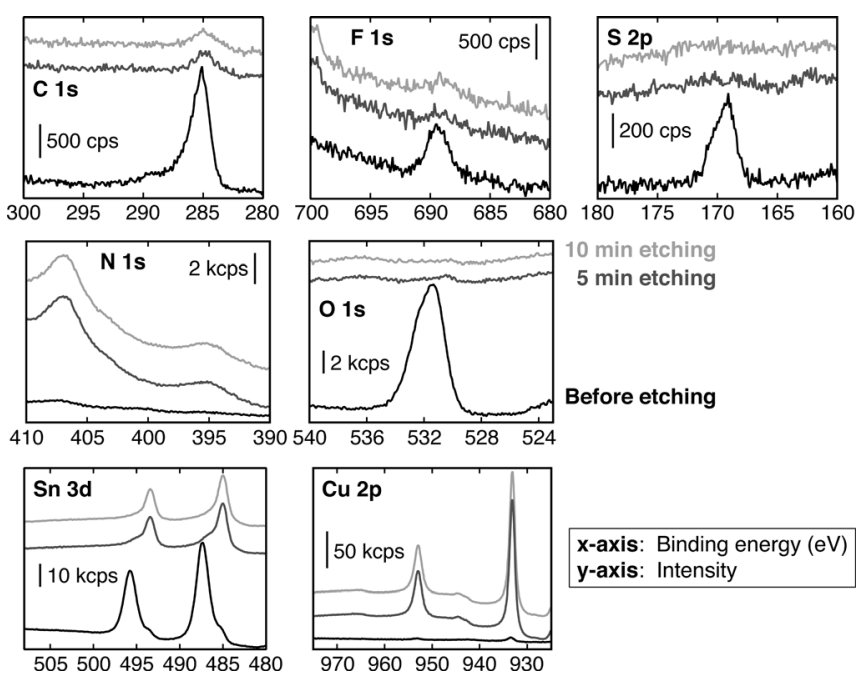

Figure 12. X-ray photoelectron spectra of $\mathrm{Cu}_{6} \mathrm{Sn}_{5}$ layer before and after Arion etching for 5 and $10 \mathrm{~min}$. The $\mathrm{Cu}-\mathrm{Sn}$ layer was prepared by galvanic contact alloying of $\mathrm{Cu}$ sheet for $72 \mathrm{~h}$ at $150^{\circ} \mathrm{C}$ using EMI- $\mathrm{Tf}_{2} \mathrm{~N}$ bath containing $0.05 \mathrm{~mol} \mathrm{dm}{ }^{-3} \mathrm{Sn}\left(\mathrm{Tf}_{2} \mathrm{~N}\right)_{2}$. 
higher than those for $\mathrm{Cu}_{6} \mathrm{Sn}_{5}$ and $\mathrm{Cu}_{3} \mathrm{Sn}$ layers. Figure 12 summarizes the XPS spectra for the $\mathrm{Cu}-\mathrm{Sn}$ layer. According to the spectra acquired before Ar-ion etching, the surface of the layer is contaminated with $\mathrm{C}, \mathrm{F}, \mathrm{S}$, and $\mathrm{O}$, which are derived from $\mathrm{EMI}^{-T f_{2} \mathrm{~N}}$. In contrast, these elements, except for a trace of carbon, were not detected after etching for 5-10 min, which corresponds to $20-40 \mathrm{~nm}$ in terms of $\mathrm{SiO}_{2}$ thickness, suggesting that the non-faradaic inclusion of solute and/or solvent, i.e. EMI- $\mathrm{Tf}_{2} \mathrm{~N}$ here, hardly takes place, unlike the cases of conventional alloy electrodeposition. This is one important feature of alloying using the RD method. In addition, the XPS spectra indicate the alloy surface to be covered with an almost $\mathrm{Cu}$-free $\mathrm{SnO}_{x}$ layer, which might be related to the corrosion resistance of the $\mathrm{Cu}-\mathrm{Sn}$ alloy. On the other hand, the residual ionic liquid on the surface may improve the corrosion behavior. However, it seems less likely since $\mathrm{Cu}-\mathrm{Sn}$ speculum layers prepared from aqueous alloy electrodeposition ${ }^{14}$ also show similar corrosion resistance.

\section{Conclusions}

In the present study, $\mathrm{Cu}$ thin layer electroless deposition on a heat-resistant high- $T_{\mathrm{g}}$ glass epoxy substrate was attempted for use as a $\mathrm{Cu}$ substrate for reduction-diffusion (RD) alloying in an ionic liquid-based bath containing $\mathrm{Sn}^{2+}$ ions at $150^{\circ} \mathrm{C}$. The part of the $\mathrm{Cu}$ layer immersed into the alloying bath was converted to a compact and adhesive silver-white $\mathrm{Cu}-\mathrm{Sn}$ "speculum alloy" layer composed of intermetallic phases, $\mathrm{Cu}_{6} \mathrm{Sn}_{5}$ and/or $\mathrm{Cu}_{3} \mathrm{Sn}$. As a result, we demonstrated the first alloy metallization of a non-conductive polymer substrate through successive electrochemical deposition using two baths, each containing different metal ions, i.e. $\mathrm{Cu}^{2+}$ and $\mathrm{Sn}^{2+}$. The abundance of the two $\mathrm{Cu}-\mathrm{Sn}$ intermetallic phases could easily be controlled by an appropriate choice of applied potential and alloying time, in which a Sn reference electrode played a significant role for stable process operation. Taking advantage of the potential-dependent alloying process, the color and anodic behavior, which are important properties of the $\mathrm{Cu}-\mathrm{Sn}$ layer as an alternative to nickel undercoating, were compared between single-phase $\mathrm{Cu}_{6} \mathrm{Sn}_{5}$ and $\mathrm{Cu}_{3} \mathrm{Sn}$. While both the phases exhibited passivation behaviors like nickel in diluted $\mathrm{H}_{2} \mathrm{SO}_{4}$ solution, they had different color shades, i.e. white-silver and bluish silver, respectively, and it was found that the color of the $\mathrm{Cu}_{6} \mathrm{Sn}_{5}$ was more appropriate as a nickel substitute.

The nonvolatile and nonflammable ionic liquid solvents were tailored for the present RD alloying. Aqueous baths cannot be used at $150^{\circ} \mathrm{C}$ without a pressure-tight vessel. Organic solvent-based baths, if any, are volatile and flammable, making the working conditions of electroplaters hazardous. Baths using high temperature molten salts generally require a glove box to avoid moisture. Most of the studies on electrodeposition using ionic liquids take advantage of their wide electrochemical window. In contrast, the target element of the present research, i.e. $\mathrm{Sn}$, is a metal that can electrodeposit from aqueous baths. Therefore, the RD process offers a new type of application for ionic liquids in this field, using their nonvolatile and nonflammable natures at medium-low temperatures while ignoring the nature of the wide electrochemical window. In this study, however, we cheated a little in selecting the polymer substrate for initial copper electroless deposition. We prepared the polymer substrate with a roughened surface by dissolving away the $\mathrm{Cu}$ layer of commercially available copper foil-clad laminate, so in this sense it is not surprising that the resulting $\mathrm{Cu}-\mathrm{Sn}$ layers had a good adhesiveness. This procedure was a temporary expedient to get a roughened epoxy substrate for various experiments, but is of course not realistic for practical processes. On the other hand, as far as we know, a convenient roughening procedure for epoxy substrates has not yet been established, unlike the case of ABS resin. Studies on chemical/ physical etching of epoxy substrate are currently underway in our group.

\section{Acknowledgments}

This work was partially supported by a Grant-in-Aid for Scientific Research (no. 21360369) from the Japan Society for the Promotion of Science (JSPS) and Kyoto University Global COE Program, "International Center for Integrated Research and Advanced Education in Materials Science" from the Ministry of Education, Culture, Sports, Science, and Technology of Japan.

Kyoto University assisted in meeting the publication costs of this article.

\section{References}

1. A. Brenner, Electrodeposition of Alloys - Principles and Practice, Vol. 1, p. 7 , Academic, New York (1963).

2. T. Katase, R. Kurosaki, K. Murase, T. Hirato, and Y. Awakura, Electrochem. Solid-State Lett., 9, C69 (2006).

3. K. Murase, R. Kurosaki, T. Katase, H. Sugimura, T. Hirato, and Y. Awakura, J. Electrochem. Soc., 154, D612 (2007).

4. A. Ito, K. Murase, T. Ichii, and H. Sugimura, Electrochemistry, 77, 677 (2009).

5. K. Murase, A. Ito, and H. Sugimura, ECS Trans., 11(28), 103 (2008).

6. N. Tachikawa, N. Serizawa, Y. Katayama, and T. Miura, Electrochim. Acta, 53, 6530 (2008).

7. Electrodeposition from Ionic Liquids, F. Endres, A. P. Abbott, and D. R. MacFarlane, Editors, p. 296, Wiley-VCH Verlag, Weinheim (2008).

8. K. Murase, K. Nitta, T. Hirato, and Y. Awakura, J. Appl. Electrochem., 31, 1089 (2001).

9. T. Katase, K. Murase, T. Hirato, and Y. Awakura, J. Appl. Electrochem., 37, 339 (2006).

10. K. Murase and Y. Awakura, Trans. Mater. Res. Soc. Jpn., 29(1), 55 (2004).

11. B. C. M. Martindale, S. E. Ward Jones, and R. G. Compton, Phys. Chem. Chem. Phys., 12, 1827 (2010).

12. N. Saunders and A. P. Miodownik, in Phase Diagrams of Binary Copper Alloys, P. R. Subramanian, D. J. Chakrabarti, and D. E. Laughlin, Editors, Monograph Series on Alloy Phase Diagrams 10, p. 412, ASM International, Materials Park, OH (1994).

13. J.-H. Shim, C.-S. Oh, B.-J. Lee, and D. N. Lee, Z. Metallkd., 87, 205 (1996).

14. T. Nakamura, Y. Mizutani, T. Nagayama, N. Shinohara, and H. Nawafune, Hyomen Gijutsu, 55, 484 (2004). 